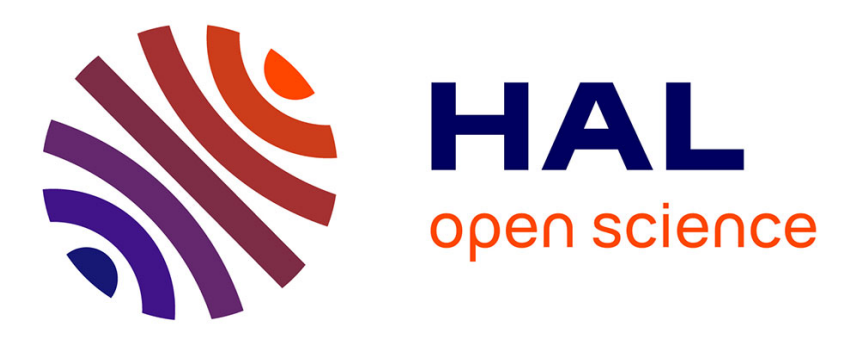

\title{
Microstructural and micro-electrochemical study of a tantalum-titanium weld interface
}

D. Grevey, V. Vignal, Issam Bendaoud, P. Erazmus-Vignal, I. Tomashchuk, Dominique Daloz, P. Sallamand

\section{- To cite this version:}

D. Grevey, V. Vignal, Issam Bendaoud, P. Erazmus-Vignal, I. Tomashchuk, et al.. Microstructural and micro-electrochemical study of a tantalum-titanium weld interface. Materials \& Design, 2015, 87, pp.974-985. 10.1016/j.matdes.2015.08.074 . hal-01291763

\section{HAL Id: hal-01291763 \\ https://hal.science/hal-01291763}

Submitted on 11 Dec 2018

HAL is a multi-disciplinary open access archive for the deposit and dissemination of scientific research documents, whether they are published or not. The documents may come from teaching and research institutions in France or abroad, or from public or private research centers.
L'archive ouverte pluridisciplinaire HAL, est destinée au dépôt et à la diffusion de documents scientifiques de niveau recherche, publiés ou non, émanant des établissements d'enseignement et de recherche français ou étrangers, des laboratoires publics ou privés. 


\title{
Microstructural and micro-electrochemical study of a tantalum-titanium weld interface
}

\author{
D. Grevey ${ }^{\text {a }}$, V. Vignal ${ }^{\text {a }}$, I. Bendaoud a ${ }^{\text {a }}$ P. Erazmus-Vignal ${ }^{a}$, I. Tomashchuk ${ }^{a}$, D. Daloz ${ }^{\text {b }}$, P. Sallamand ${ }^{\text {a, }}$ \\ a Laboratoire Interdisciplinaire Carnot de Bourgogne, UMR 6303 CNRS/Univ. de Bourgogne Franche-Comté-12, rue de la Fonderie, 71200 Le Creusot, France \\ b Institut Jean Lamour, UMR 7198 CNRS - Université de Lorraine - Parc de Saurupt, CS 50840-54011 Nancy cedex, France
}

Keywords:

Laser welding

Dissimilar materials

Electrochemical behaviour

Tantalum

Ti-6Al-4V

\begin{abstract}
A B S T R A C T
Laser welding offers an array of advantages compared to conventional fusion welding techniques, such as a higher welding speed and lower thermal distortion. However, information about the key aspects of the welding of dissimilar materials remains limited. Therefore, we chose to study the weld interface between tantalum and Ti-6Al-4V, which have good metallurgical compatibility but highly different thermophysical properties that can lead to pronounced chemical heterogeneities. An SEM analysis of the microstructure clearly revealed the formation of an unmixed zone in the melted area and a DRX analysis highlighted the presence of a $\beta(\mathrm{Ta}, \mathrm{Ti})$ solid solution, tantalum islets and possibly $\alpha$ '-titanium where betagenic tantalum was absent. In terms of electrochemical behaviour, the titanium content was the main indicator of oxidation phenomena: a content greater than $50 \%$ resulted in a stable passive film, while lower values led to an oxidation peak at approximately $1.7 \mathrm{~V} \mathrm{vs} \mathrm{Ag} / \mathrm{AgCl}$. These results suggest that a reliable laser welding process must promote a high titanium content in the melted area. This may be achieved through an optimized process with a heat source that shifts away from the tantalum in order to minimize tantalum levels in the melted area.
\end{abstract}

\section{Introduction}

The creation of a junction between two dissimilar materials by fusion can be associated with undesirable phenomena such as the formation of intermetallic compounds, the appearance of cracks induced by thermal distortion during solidification or cooling, and so on [1]. These issues are a key concern for many researchers [2-4], whose major challenges are to succeed in creating a junction between two seemingly incompatible materials, rethink the choice of materials, prepare for the arrival of smart materials, and come up with simpler designs and more desirable characteristics.

The use of an interlayer to adapt the chemistry of the melted zone is widely advocated $[5,6]$. Another possibility is to limit energy deposition at the interface in order to curb the amount of unwanted phases produced. This can be achieved with the help of rapid-kinetics fusion processes (laser [7], electron beam [8]) or non-fusion techniques such as friction stir welding [9] or diffusion bonding [10].

However, up until now, certain aspects have only been touched on, particularly those concerning heterogeneities relating to differences in the thermophysical properties of substrates. These issues, which are already considerable when the materials are chemically compatible, can become acute when combined with the chemical incompatibility

\footnotetext{
* Corresponding author.

E-mail address: pierre.sallamand@u-bourgogne.fr (P. Sallamand).
}

of materials, thus making it necessary to improve the properties of the junction. In such cases, it is not possible to design a high-performance junction as an ideal junction possessing a perfect continuity of chemical, metallurgical and mechanical properties.

In a bid to achieve better control over the melted zone, we chose to work with a material pair exhibiting total miscibility and a great difference in thermophysical properties. We decided on tantalum and titanium-more specifically a Ti-6Al-V4 alloy. The welding of these materials typically exacerbates the effects induced by fusion-bonding phenomena. Joining of dissimilar couple titanium-tantalum is very little studied. Successful joining of titanium with tantalum by resistance welding [11] and diffusion bonding [12,13] was reported. Recently, welding of pure tantalum with Ti6Al4-V alloy was carried out by Malicrot [14].

To our knowledge, the electrochemical behaviour and corrosion resistance of dissimilar Ti-6Al-4V/Ti joints have not been studied. Some papers have investigated the corrosion behaviour of Ti-Ta alloys with Ta contents between 10 and $70 \mathrm{wt} . \%$. The experiments described in these papers were conducted in $\mathrm{NaCl}$-based media for biomedical applications [15,16] and in acidic media used in the chemical industry [17]. However, the results obtained, especially those pertaining to the influence of the alloy's chemical composition, cannot be used to understand the electrochemical behaviour of dissimilar Ti-6Al-4V/Ti joints. Indeed, the microstructures of these two material pairs-dissimilar Ti-6Al-4V/Ti joints and Ti-Ta alloys-are very different and may significantly affect the electrochemical behaviour. 
In the present paper, a butt weld configuration is discussed in detail with a view to developing an optimal laser welding process. The aim of our research was to create a melted zone having equal portions of each metal. The melted zones were characterized from a microstructural and electrochemical point of view. Electrochemical investigations were carried out at the microscale and acidic solutions were used to exacerbate undesirable phenomena. These conditions enable us to propose criteria leading to significant changes in the behaviour of dissimilar Ti-6Al-4V/Ti joints. Possibilities for future process improvement are also discussed.

\section{Materials and methods}

\subsection{Materials}

The materials chosen for this study were pure tantalum and a Ti-6Al-4V titanium alloy (Table 1). This pair was selected for the significant differences in their thermophysical properties, as shown in Table 2. Most notably, the melting temperature of tantalum is much higher than that of the titanium alloy and is close to the vaporization temperature of titanium. These differences promote the creation of chemical heterogeneities in the melted zone [14].

Furthermore, titanium is completely soluble in $\beta$-phase tantalum [18] and results in the formation of a substitutional solid solution, $\beta(\mathrm{Ti}, \mathrm{Ta})$. In addition, according to the binary phase diagrams and some preliminary experiments, the alloying elements ( $\mathrm{Al}, \mathrm{V})$ have no significant influence on the weld interface: there are no intermetallic compounds in the melted zone and the contents of aluminium and vanadium mirror that of titanium. Therefore, the selected (tantalum, titanium) pair was assumed to display simple metallurgical behaviour. The materials were plates with typical dimensions of $100 \times 20 \times 2 \mathrm{~mm}^{3}$.

\subsection{Welding method}

The well-known keyhole laser welding process [19-21] was used in a butt configuration, where laser energy is transferred via bulk absorption at the walls of a vapour capillary generated by high-intensity lasermaterial interaction. One of the advantages of the laser process over other fusion processes is the ability to provide very short durations of interaction (some tens of ms) between liquid titanium and liquid tantalum, thereby limiting the mixing of these two fluids. Another advantage of this process is that high welding speeds are usually achievable.

The process begins with laser irradiation of the surface, which melts, then vaporizes. Due to vapour ejection, the surface grows hollow and a vapour capillary develops. If the laser beam is at the border between the two abutting materials, the thermophysical properties of the materials influence the capillary growth rate.

The thermal field (Fig. 1) for our materials and welding conditions was calculated by using the Comsol Multiphysics code with a view to understanding the results (Fig. 2). Detailed description of the model is provided in Appendix A. In Fig. 1, isotherms are shown and the melting $\left(T_{f}\right)$ and vaporization $\left(T_{\text {vap }}\right)$ temperatures of the two materials are highlighted. When the laser beam is centred on the border between the two materials, titanium is the first to reach its vaporization temperature and the capillary grows in this material; this corresponds to the result in Fig. 2.a. When the beam is shifted to the most refractory material, titanium is still the first to vaporize, but the thermal field is

Table 1

Composition of Ti-6Al-4V used in this study.

\begin{tabular}{lllllllll}
\hline Element & $\mathrm{Fe}$ & $\mathrm{O}$ & $\mathrm{N}$ & $\mathrm{H}$ & $\mathrm{C}$ & $\mathrm{Al}$ & $\mathrm{V}$ & $\mathrm{Ti}$ \\
\hline wt.\% & $\leq 0.30$ & $\leq 0.20$ & $\leq 0.05$ & $\leq 0.015$ & $\leq 0.08$ & $5.5 / 6.75$ & $3.5 / 4.5$ & Balance \\
\hline
\end{tabular}

Table 2

Thermophysical properties of materials used in this study.

\begin{tabular}{lll}
\hline Physical property & Ti-6Al-4V & Ta \\
\hline Fusion temperature $T_{f}(\mathrm{~K})$ & 1878 & 3269 \\
Vaporization temperature $T_{\text {vap }}(\mathrm{K})$ & 3591 & 5698 \\
Density of liquid metal $\rho_{l}\left(\mathrm{~kg} / \mathrm{m}^{3}\right)$ & 4100 & 15,000 \\
Density of solid metal $\rho_{s}\left(\mathrm{~kg} / \mathrm{m}^{3}\right)$ & 4500 & 15,630 \\
Thermal conductivity of solid $\lambda_{s}(\mathrm{~W} / \mathrm{m} \cdot \mathrm{K})$ & 5.8 & 57.5 \\
Thermal conductivity of liquid $\lambda_{l}(\mathrm{~W} / \mathrm{m} \cdot \mathrm{K})$ & 31.2 & 66.5 \\
Specific heat of solid $c_{p s}(\mathrm{~J} / \mathrm{kg} \cdot \mathrm{K})$ & 550 & 140 \\
Specific heat of liquid $c_{p l}(\mathrm{~J} / \mathrm{kg} \cdot \mathrm{K})$ & 895.2 & 213 \\
Latent heat of melting $L_{f}(\mathrm{~kJ} / \mathrm{kg})$ & $3.9 \cdot 10^{5}$ & $1.7 \cdot 10^{5}$ \\
Absorption coefficient $a(\%)$ & 40 & 12 \\
\hline
\end{tabular}

more balanced and the capillary develops in both materials, at least in the upper part of the seam (Fig. 2.b). The transient temperature field may be determined by solving the two-dimensional heat equation [22]. In this system, the heat source is static and metallurgical phenomena are not taken into consideration. The energy contribution of the laser is approximated as a Gaussian surface heat source introduced as a surface boundary condition. We chose this approach to highlight the influence of the differential between thermophysical properties during heating until the occurrence of vaporization. After vaporization, the capillary develops and another type of model has to be implemented. In this investigation, we only studied the first stage of heating, that is, until the vaporization temperature is reached. According to the thermal field, vaporization occurs after approximately $0.1 \mathrm{~ms}$ for titanium and several $\mathrm{ms}$ for tantalum. Moreover, when titanium vaporization begins, the surface temperature of titanium is approximately $300^{\circ} \mathrm{C}$ higher than that of tantalum, due to the difference in their diffusivities (Fig. 1.b.). Thus, we can assume that the capillary develops preferentially in titanium and leads to instabilities (Fig. 2.a.). One technological solution to these problems is to partially switch the laser beam over to the tantalum side. Figs. 1.a. and 2.b. illustrate the case where the axis of the laser beam is shifted by $0.2 \mathrm{~mm}$ from the joint line to the tantalum zone. They indicate a higher temperature in the tantalum and a more acceptable melting zone. In this configuration, despite the observed asymmetry, the strength of the weld fulfils classical requirements.

Therefore, a butt configuration was used in this study. Such a configuration consists in delivering the beam at the interface between the two plates, with a $0.2 \mathrm{~mm}$ shift in the tantalum direction, and is qualitatively based on the refractory behaviour of tantalum with respect to that of titanium, as described above.

A Trumpf Yb:YAG (Yttrium and Aluminium Garnet) laser was used. The beam was delivered to the target via a $600 \mu \mathrm{m}$ optical fibre and a focusing optical system with a magnification of 1 . Thus, the spot diameter of the beam on the surface of the target was $600 \mu \mathrm{m}$. Argon was used as a shielding gas to avoid oxidation during the welding process and different operational parameters were employed to obtain melted zones with varying levels of chemical heterogeneity (Table 3 ).

\subsection{Characterization methods}

After welding, metallographic specimens were prepared according to standard procedures: use of a Presi composite range until $1 \mu \mathrm{m}$ and finishing with a vibratory polishing machine. Microstructures were observed by means of a JEOL scanning electron microscope (SEM), and the chemical composition of different parts of the melted zone were analysed by an energy dispersive spectrometer (EDS) integrated in the SEM system. During EDS, the focal spot size and the effective testing area were less than $5 \mu \mathrm{m}$ for a point analysis, and a rectangle of approximately $90 \times 100 \mu^{2}$ was also examined for a more global view. The relative error was less than $0.5 \%$. An EBSD system was also used (TSL EDAX: 120 pts/s step size $30 \mathrm{~nm}$, low mag map available). 


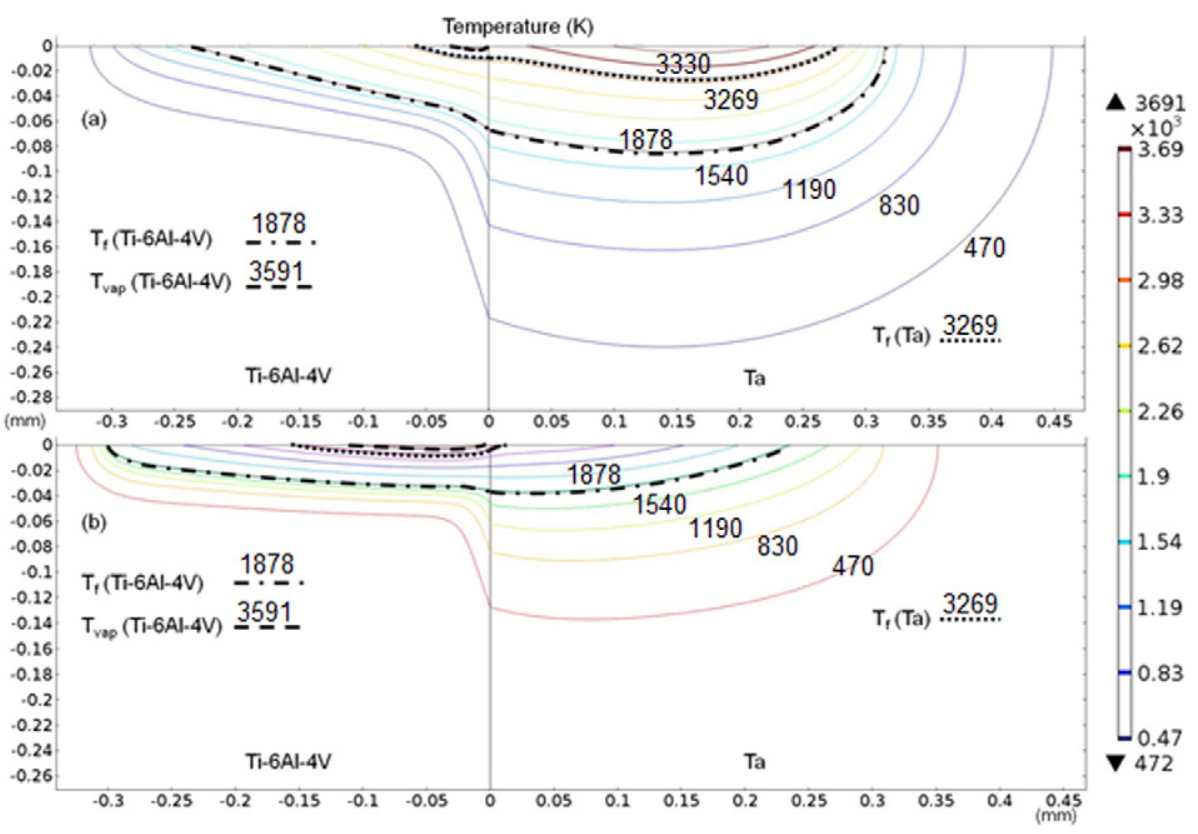

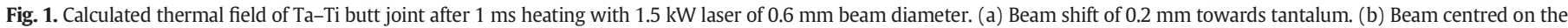
interface between the two materials. The area above each curve corresponds to the area heated by the laser and the vertical axis represents the depth.

These observations were complemented by the use of an X-ray diffractometer (XRD, PANalytical XPert) comprising a mono-capillary optics module with Co K $\alpha$ radiation, with $\lambda=0.1789010 \mathrm{~nm}$, a 20-range of $35-120^{\circ}$, a scan rate of $4.5^{\circ} \mathrm{h}^{-1}$ and a beam size of $100 \mu \mathrm{m}$.

Local electrochemical investigations were performed in $0.1 \mathrm{M} \mathrm{HCl}$ at $25{ }^{\circ} \mathrm{C}$ by using the electrochemical microcell technique [23] and an Autolab PG128 electrochemical interface. The capillary tip (diameter of $30 \mu \mathrm{m}$ ) was adhered to the specimen surface with a layer of silicon rubber. The wetted area on the specimen was accurately calculated using a specific image analysis procedure. Potentials were measured vs. $\mathrm{Ag} / \mathrm{AgCl}(3 \mathrm{M} \mathrm{KCl})$ and the counter electrode was made of platinum wire. Polarization curves were plotted at a scan rate of $1 \mathrm{mV} / \mathrm{s}$, from an applied potential of $-1 \mathrm{~V}$ vs. $\mathrm{Ag} / \mathrm{AgCl}$ to $+2.2 \mathrm{~V}$ vs. $\mathrm{Ag} / \mathrm{AgCl}$. No prior polarization was applied in the cathodic domain.

\section{Results and discussion}

\subsection{Solidification microstructure}

Figs. 3 and 4 show the typical macrostructures obtained with a beam shift to the tantalum side. We may observe that the axis of symmetry of the molten zone was displaced towards the titanium despite the significant beam shift towards the tantalum. This must have been a direct consequence of the difference in the thermal characteristics of the two materials, as discussed above in relation to Fig. 1.

The SEM images obtained indicate a high level of chemical heterogeneity in the molten zone. Fig. 3 presents two seams with low penetrations and shows that convection governed the distribution of elements at this scale. Indeed, the interaction time was limited to a few tens of milliseconds. Other phenomena, such as interfacial tension, viscosity and material density might have contributed to this. Diffusion phenomena most certainly played a role in the homogenization of the composition on the scale of the microstructure.

Several aspects characterize the molten areas. According to global analyses (see Table 4 and Fig. 5), titanium is always accompanied by its alloying elements, whose amounts vary according to the variations in the titanium content. Furthermore, a geometric analysis shows that the molten zone contains between 30 and $40 \%$ tantalum, which is unevenly distributed.

In Sample C, which is the most representative of a real laser welding process among the three samples, these heterogeneities are reflected in the presence of tantalum islets embedded here and there in the solid
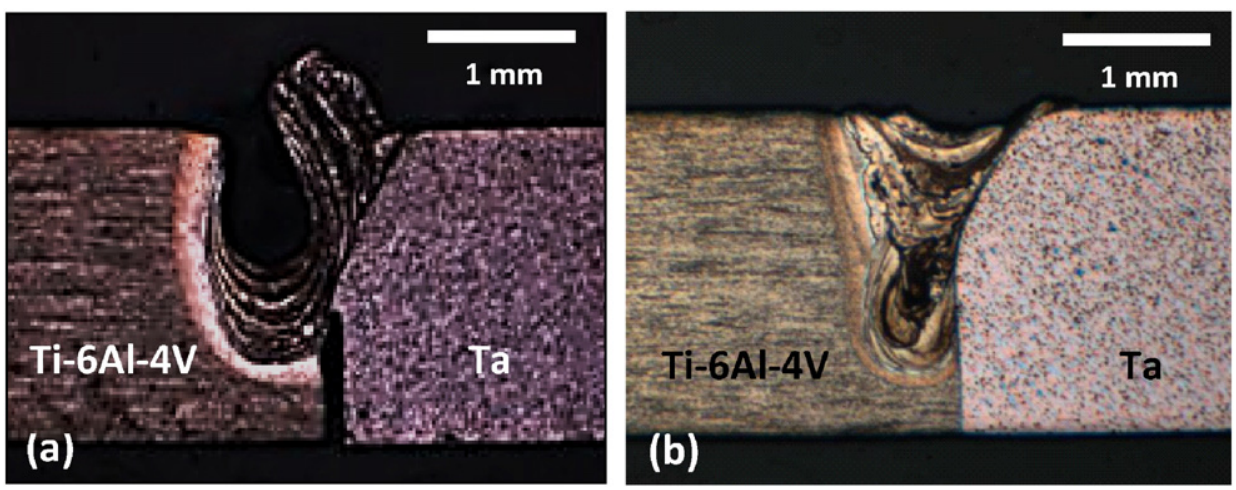

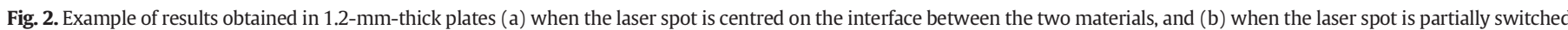
over to the tantalum side [14]. 
Table 3

Experimental conditions for sample production.

\begin{tabular}{lll}
\hline Sample & Working speed $\left(\mathrm{m} \cdot \mathrm{min}^{-1}\right)$ & Laser power $(\mathrm{kW})$ \\
\hline A & 4 & 1.5 \\
B & 6 & 1.5 \\
C & 2 & 1.5 \\
\hline
\end{tabular}

solution ( $\beta \mathrm{Ti}, \mathrm{Ta})$. This observation corroborates the results obtained by Malicrot [14]. Some of these islets have been completely or partially melted (Fig. 6), while others have remained in the solid state (Fig. 7). All of them are scattered throughout all parts of the molten zone, although fewer islets are observed in the lower part of the seam. The centres of the partially melted islets contain nearly $90 \%$ tantalum, as shown in Table 4 (Landmark 7 - local analysis - light area). Sometimes a plane front of solidification is visible on the periphery of the islets (Fig. 6b), indicating where inversion of the thermal gradient occurred during the fusion-solidification process. This confirms that only the periphery of these islets was affected by the melting.

Samples A and B are very interesting from a phenomenological point of view as they reveal how the tantalum islets are incorporated into the molten zone. Because the welding speeds for Samples A and B were much higher than for Sample C, we can assume that these samples represent an intermediate state between the initial state and that of Sample C. The upper part of the molten tantalum is incorporated in the "mixture" by convection. Indeed, at the bottom part, a titanium tongue penetrates into the tantalum because of a dissolution effect, and the movement of the liquid caused fragmentation of the liquid tantalum in the centre of the molten zone. An SEM analysis of Sample B shows that some solid tantalum islets were also moved, probably due to titanium infiltration at the tantalum grain boundaries. This hypothesis is based on the observation of a higher titanium content in the grain boundaries of the islets that had moved. However, the low volumes involved prevent us from quantifying the exact content. This titanium enrichment process is better highlighted at Landmark 2 in Sample A (Fig. 8a). This micrograph demonstrates that the titanium infiltrated preferentially along the grain boundaries (dark zones), then diffused into the grain. Table 4 shows that the grain centres (light areas) contain approximately $30 \mathrm{wt} . \%$ titanium while areas near grain boundaries contain approximately $50 \mathrm{wt}$.\% titanium. This effect is somewhat less pronounced at the border of the molten zone near the tantalum substrate (Fig. 8b).

An XRD analysis carried out at Landmarks 1, 2 and 5 in Sample A (Fig. 9) indicates the presence of $\beta$ (Ta,Ti) solid solution, tantalum, $\beta$-titanium, and $\alpha$-titanium that could be $\alpha^{\prime}$-titanium because of the rapid cooling cycle. Because $\beta$-titanium and tantalum have similar atomic radii $(\approx 0.2 \mathrm{~nm}$ ) and are isomorphic (bcc structure with a lattice parameter of approximately $332 \mathrm{pm}$ ), their peaks coincide and also

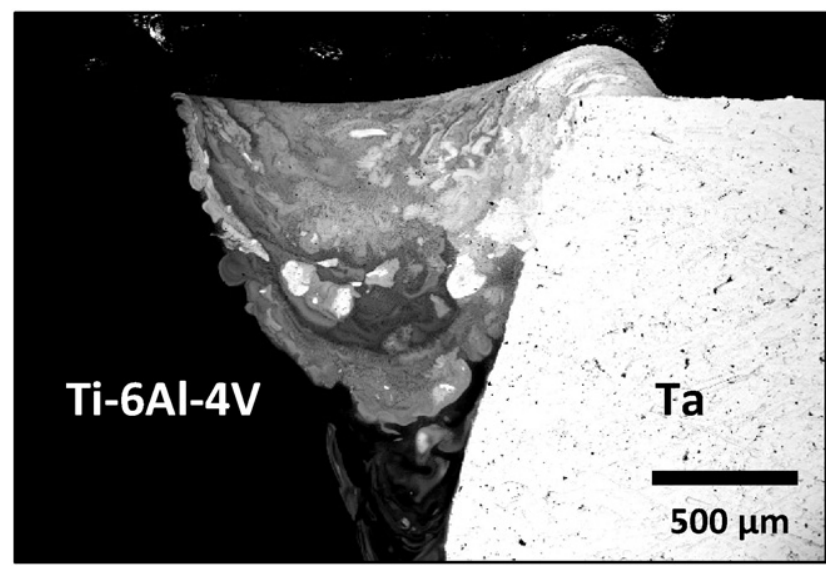

Fig. 4. Cross-section of Sample C [BSE mode].

share the same locations as the peaks for the $\beta(\mathrm{Ta}, \mathrm{Ti})$ solid solution. Therefore, based on this and the corresponding SEM analyses, we can assume that $\beta(\mathrm{Ta}, \mathrm{Ti})$ solid solution and tantalum islets were the two main phases.

The peak intensities for $\alpha$-titanium are low and may be attributed to the small amount of this phase and the small volume that was investigated. Moreover, given the large quantities of betagenic tantalum in the melted area (45, 60 and 80\% at Landmarks 1, 2 and 5 respectively), the $\alpha$-titanium phase can only be found locally, where the tantalum content is very low. These results are in close agreement with Malicrot's observations [14].

Two types of structures can be identified in the solid solution: i) a columnar structure observable near the base metals and the tantalum islets, where solidification generally began with a plane front (Figs. 6, 7 and 10), and ii) a large, mainly equiaxed structure reflecting the growth of nuclei in a supercooled area. The equiaxed grains, measuring between 2 and $100 \mu \mathrm{m}$, originated from the tantalum particles (Fig. 11). The transition area between the columnar and equiaxed structures was influenced by the composition of the heterogeneous mixture, by convection and by thermal gradients. Thus, it appears that the presence of tantalum nuclei promotes an equiaxed structure while classical laser welding is associated with a columnar structure that develops from the boundary of the melted zone (interface between the base metal and the melted zone) until the centre of the seam.

Specific EBSD analyses of Landmarks 1 and 2 reveal two different structures, both of which are composed of large grains. We may observe an intragranular disorientation at Landmark 2 and the existence of a very fine intragranular structure at Landmark 1 . These differences can explain the differential response of the materials during X-ray diffraction analysis (lower peak around $45^{\circ}$ and wider peaks).
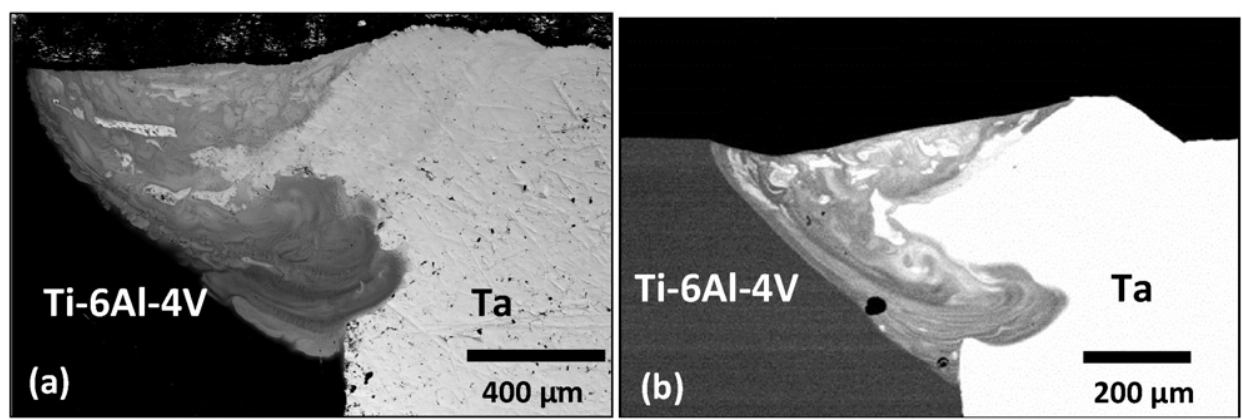

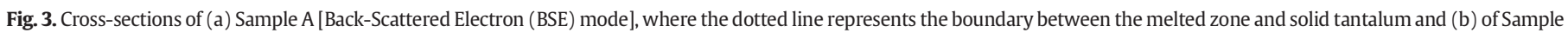
B [BSE mode]. 
Table 4

EDS analysis of Sample A. The average values were obtained by analysing a $90 \times 100 \mu \mathrm{m}^{2}$ rectangular area. The light and dark zones correspond to selected point analyses of Landmarks are shown in Fig. 8.

\begin{tabular}{|c|c|c|c|c|}
\hline & \multicolumn{4}{|c|}{ Elemental composition (wt \%) } \\
\hline & Ta & $\mathrm{Ti}$ & Al & V \\
\hline \multicolumn{5}{|l|}{ Landmark 1} \\
\hline Light zone & 39 & 55 & 3 & 3 \\
\hline Dark zone & 32 & 61 & 4 & 3 \\
\hline Average & 45 & 49 & 3 & 2 \\
\hline \multicolumn{5}{|l|}{ Landmark 2} \\
\hline Light zone & 64 & 32 & 2 & 2 \\
\hline Dark zone & 46 & 48 & 3 & 3 \\
\hline Average & 60 & 37 & 2 & 2 \\
\hline \multicolumn{5}{|l|}{ Landmark 3} \\
\hline Light zone & 81 & 16 & 1 & 1 \\
\hline Dark zone & 10 & 81 & 5 & 3 \\
\hline Average & 68 & 29 & 2 & 1 \\
\hline \multicolumn{5}{|l|}{ Landmark 5} \\
\hline Light zone & 90 & 10 & $<1$ & $<1$ \\
\hline Dark zone & 75 & 23 & 1 & 1 \\
\hline Average & 80 & 18 & 1 & 1 \\
\hline \multicolumn{5}{|l|}{ Landmark 6} \\
\hline Light zone & - & - & - & - \\
\hline Dark zone & - & - & - & - \\
\hline Average & 29 & 64 & 4 & 3 \\
\hline \multicolumn{5}{|l|}{ Landmark 7} \\
\hline Light zone & 99 & 0 & 1 & 0 \\
\hline Dark zone & 37 & 58 & 4 & 1 \\
\hline Average & 41 & 53 & 4 & 2 \\
\hline \multicolumn{5}{|l|}{ Landmark 8} \\
\hline Light zone & - & - & - & - \\
\hline Dark zone & - & - & - & - \\
\hline Average & 88 & 11 & $<1$ & $<1$ \\
\hline
\end{tabular}

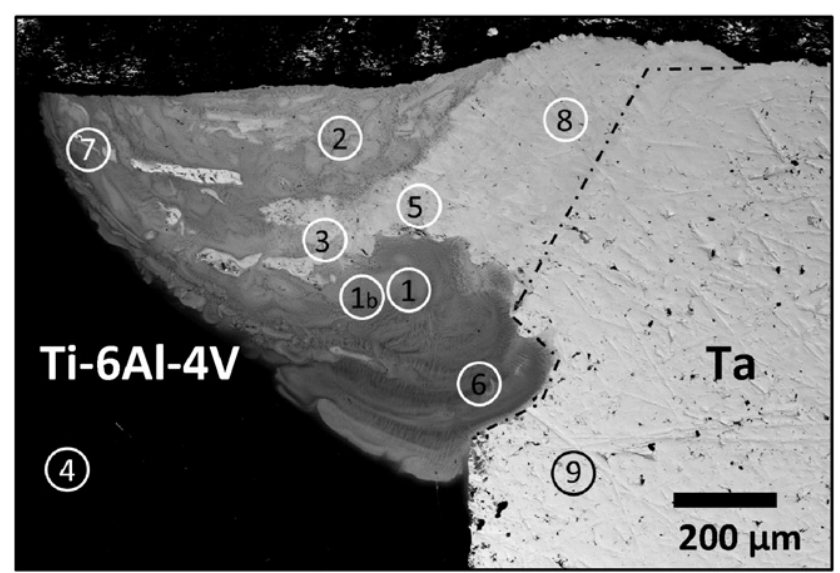

Fig. 5. Landmarks of areas of characterization in Sample A.
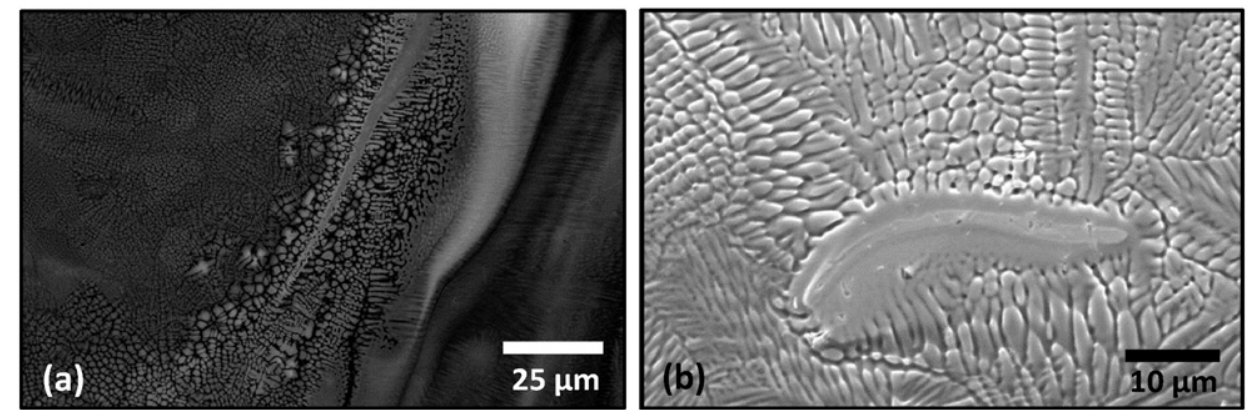

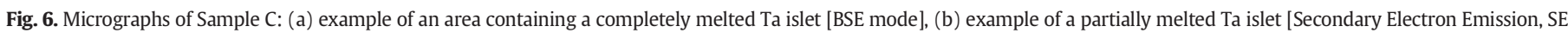
mode] [14].

The microstructure of the grains is reflective of cellular-dendritic growth. Indeed, a cellular microstructure is visible near the Ta-rich areas. The width of the cells measures between 1 and $3 \mu \mathrm{m}$, and the maximum length, which is not easily distinguishable, is approximately $100 \mu \mathrm{m}$. The cells surrounding a given block have very similar compositions of between 70 and 80 wt.\% Ta (i.e. between 40 and 60 at.\% Ta). These percentages are higher than the average percentage of Ta in the solid solution (30-50 wt.\%, for example Landmarks 1, 6, 7 in Table 4) because the melting/dissolution islets enriched their immediate environment with tantalum (Fig. 12).

A dendritic microstructure is visible in islet-free areas. The dendrites have a wide range of sizes and an average composition of approximately $40 \mathrm{wt}$.\% Ta. Measurements show a maximum primary-trunk length of $100 \mu \mathrm{m}$ and an average interdendritic spacing of $3 \mu \mathrm{m}$. The cells and the dendrites, which have the highest Ta contents, exhibit the smallest interdendritic spacing. As the starting temperature for solidification must have varied greatly-according to variations in the local tantalum content-the orientation of the dendrites is very random and some shrinkage defects can be seen (Fig. 13). Such orientation randomness and shrinkage defects are related to compositional heterogeneities that cause chaotic solidification and dimensional reduction, brought about by a reduction in the volume of the melted material as it cools and solidifies. In our investigation, the presence of tantalum islets reinforced this phenomenon.

\subsection{Electrochemical behaviour}

Electrochemical microanalyses were performed for several marked surface regions on Sample A. This enabled us to characterize the electrochemical behaviour of each of the different zones encountered in the molten zone. The chemical composition of the various marked surface regions was previously determined by EDS. Fig. 14 shows the two types of polarization curves obtained, which indicate the presence of two or three plateaus in the anodic domain. As shown in Table 5, there were only two plateaus, P1 and P2, for a titanium content exceeding $50 \%$ (Fig. 14a). A third plateau, P3, appeared when the tantalum content exceeded 50\% (Fig. 14b). In addition, the potential at which the P1/P2 transition was observed increased linearly with increasing titanium content (Fig. 15). The transition potential is defined in Fig. 14. Therefore, the electrochemical behaviour of Sample A was governed by its chemical composition.

In a previous study, it was shown that for TA-6Al-4V in sodium chloride solution [24], the P1 plateau corresponds to the formation of a passive film that behaves like a blocking electrode. It was also demonstrated that during the P2 plateau, the passive film undergoes structural changes (increase in defect density) and becomes less protective. During the P3 plateau, pitting corrosion was observed [24]. This explains why surface regions of Sample A containing large amounts of titanium exhibited a large P1 plateau and possessed better corrosion 


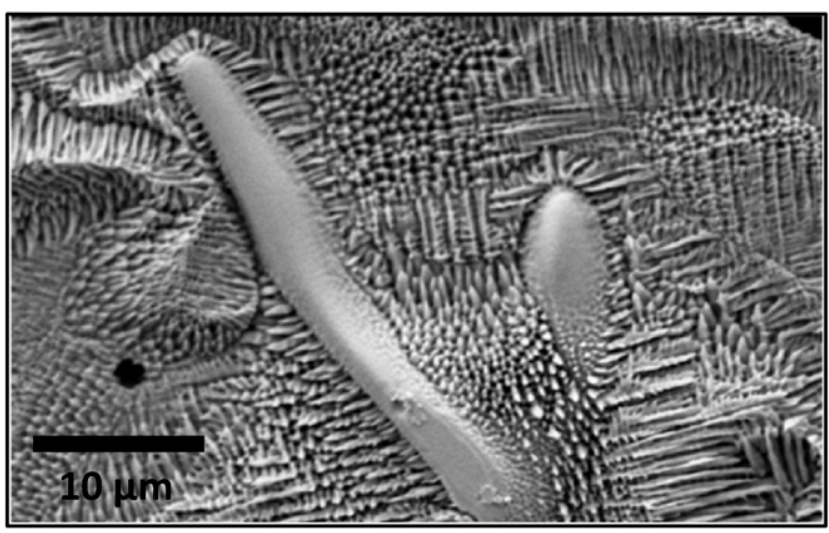

Fig. 7. Ta islet that remained solid in Sample C [SE mode] [14].

resistance than other areas. By contrast, surface regions containing large amounts of tantalum (greater than $50 \%$ ) were susceptible to pitting corrosion (within the potential range located in the P3 plateau). Indeed, at the onset of the P3 plateau, an oxidation peak was detected (Fig. 14b and c). The peak intensity did not seem to depend on the local tantalum content. Numerous current fluctuations were observed within this potential range, confirming that corrosion did indeed develop.

To confirm the above hypotheses, electrochemical tests under potentiostatic control (at $2 \mathrm{~V}$ vs. $\mathrm{Ag} / \mathrm{AgCl}$ ) were carried out for Landmarks 1 (titanium content $>50 \%$, plateau P3 not observed) and 5 (tantalum content $>50 \%$, plateau P3 observed); the results of these tests are shown in Fig. 16. In the case of Landmark 1, the current density decreased sharply before reaching a steady-state value of $0.0037 \mathrm{~mA} / \mathrm{cm}^{2}$, whereupon it remained relatively low and very stable. By contrast, large current density fluctuations were detected at Landmark 5 as soon as the test was started. In addition, the steady-state current density was high, registering approximately $0.2 \mathrm{~mA} / \mathrm{cm}^{2}$, or 50 times greater than that at Landmark 1 . These results confirm that corrosion occurred at Landmark 5 where the tantalum content was greater than $50 \%$.

Landmark 2, which is close to the surface (Fig. 5), displayed singular behaviour. Indeed, the P2 plateau was broken at approximately $1.5 \mathrm{~V}$ vs. $\mathrm{Ag} / \mathrm{AgCl}$ (Fig. 17), at which point the current density increased continuously. Neither the oxidation peak corresponding to the P2/P3 transition nor the P3 plateau was observed. This singular behaviour may be explained by considering the results from the XRD measurements (Fig. 9) and the EBSD analysis (Fig. 18) for this surface region. For example, differences in intragranular disorientation could explain that Landmark 2 was more sensitive to oxidation because of larger and heterogeneous grains, as opposed to Landmark 1 , which possesses a finer and more homogeneous structure. Thus, we can assume that the microstructure had a dominant influence at Landmark 2.
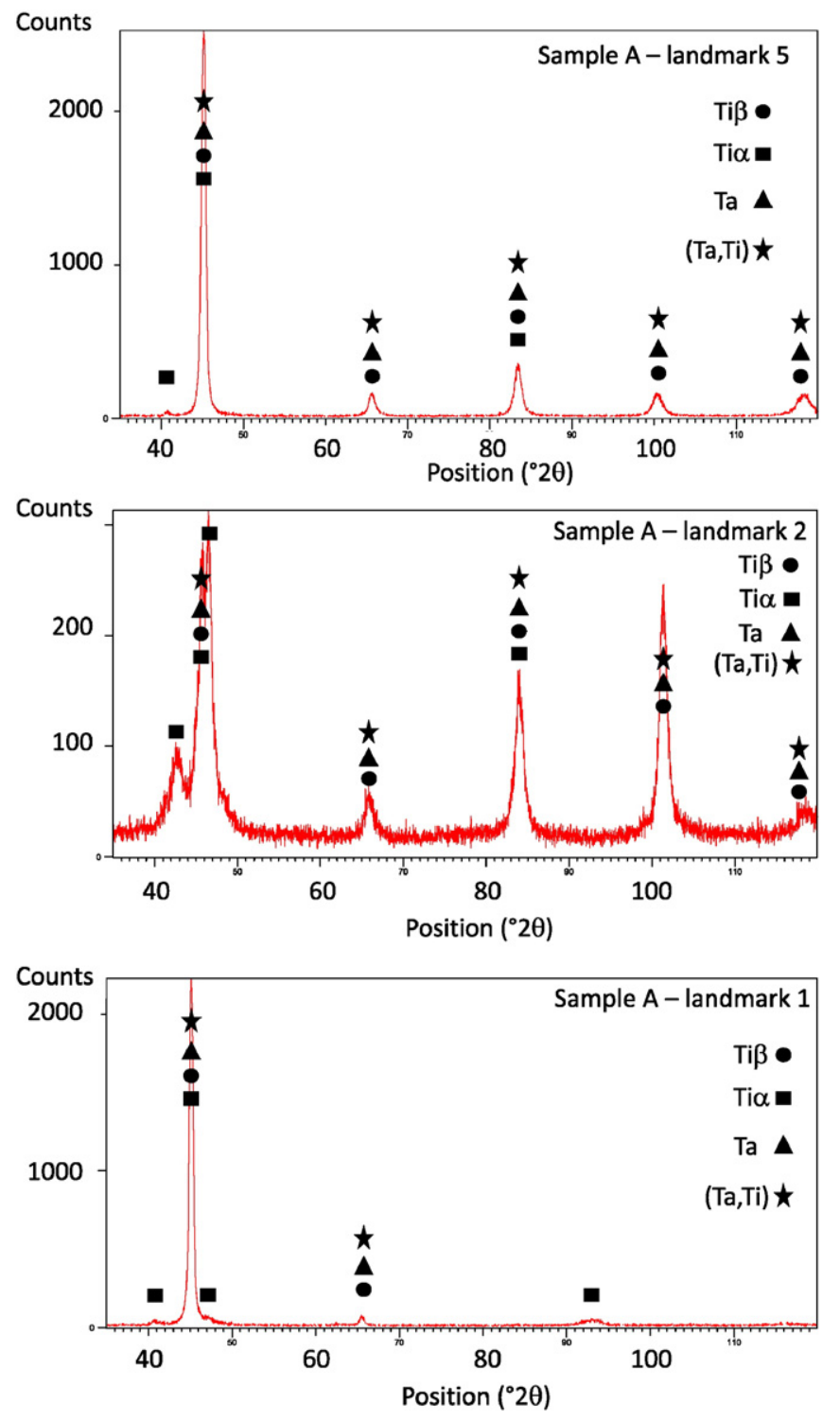

Fig. 9. Mono-capillary DRX analysis of different zones in Sample A.

The current density measured in the cathodic domain also depended on the local chemical composition of Sample A, as shown in Fig. 19. When the $\mathrm{Al} / \mathrm{V}$ ratio was greater than 1.4 , the current density measured on local polarization curves at an arbitrary applied cathodic potential of $-750 \mathrm{mV}$ vs. Ag/AgCl was relatively low (average value of approximately
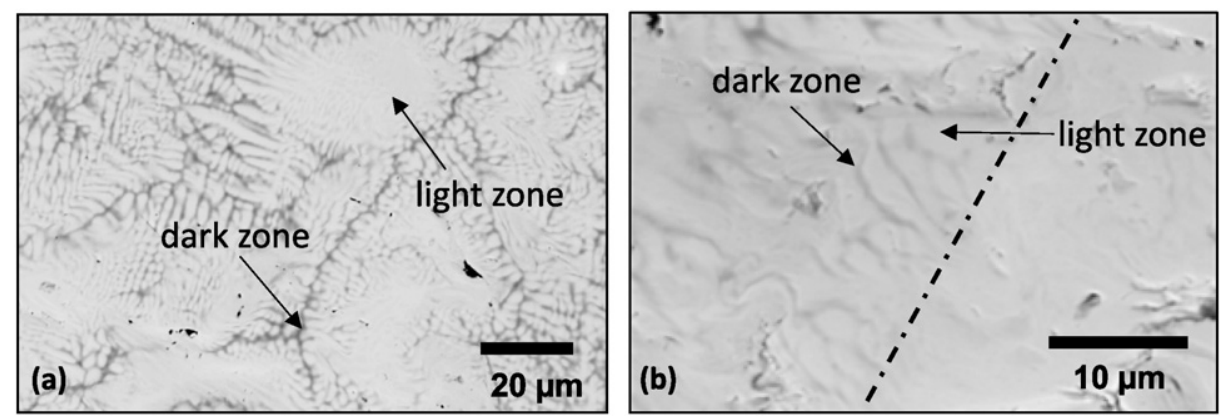

Fig. 8. Micrographs of Sample A [BSE mode]. (a) SEM image of the microstructure near Landmark 2. (b) SEM image of the border of the melted zone (tantalum side). 

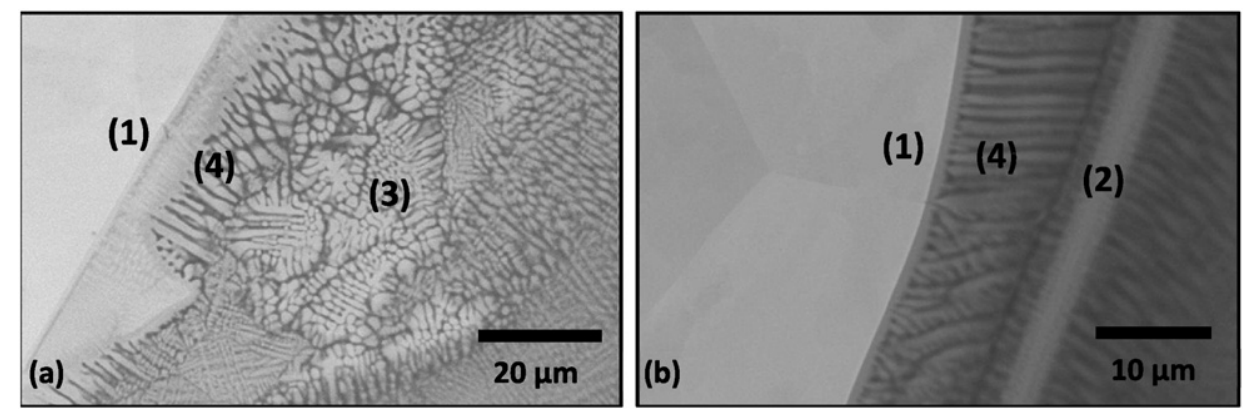

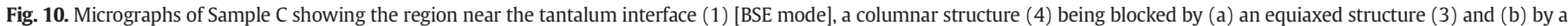
tantalum islet (2) [14].
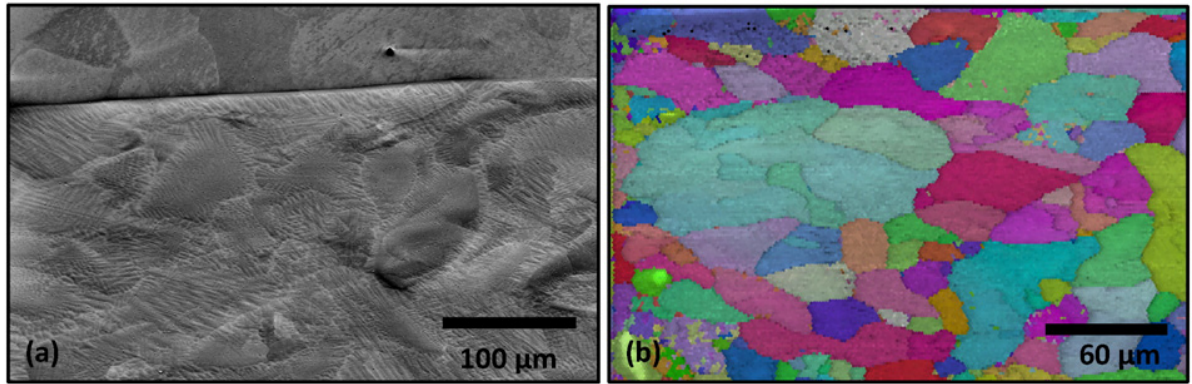

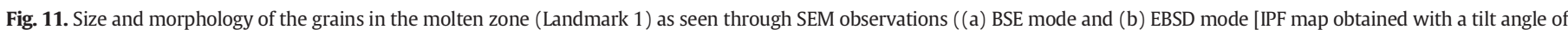
$\left.\left.70^{\circ}\right]\right)$.

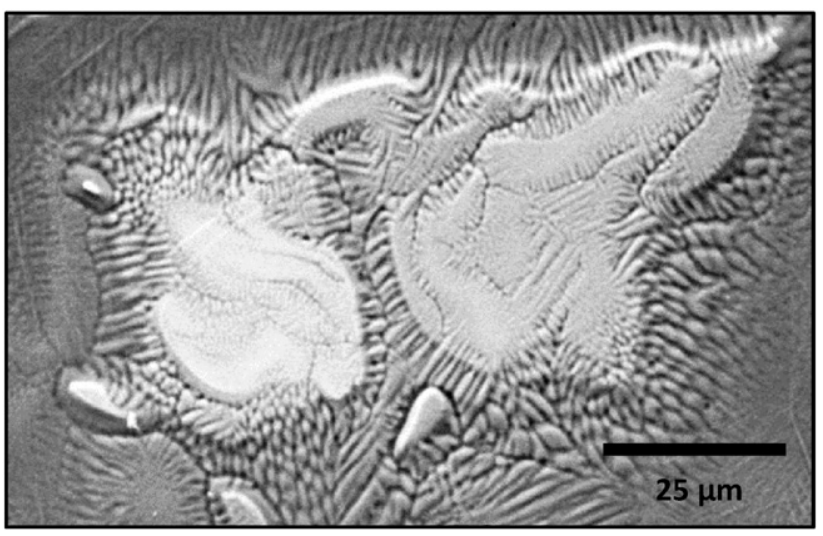

Fig. 12. SE image of a tantalum islet that froze during dissolution in Sample C [14].

$\left.70 \mu \mathrm{A} / \mathrm{cm}^{2}\right)$. The current density was significantly greater when this ratio was lower than 1.4 (average value of $420 \mu \mathrm{A} / \mathrm{cm}^{2}$ ). These results are consistent with those published in [24] where it was shown that the presence of aluminium in the passive film hinders cathodic reactions.

\subsection{Process improvement}

The welding configuration that led to the seam shown in Fig. 2.b. is satisfactory for industrial applications where static mechanical strength is required. In contrast, all the above observations confirm that the molten zones obtained under these conditions (beam shift towards tantalum) lead to heterogeneities that promote the appearance of solidification defects as well as chemical and microstructural heterogeneities that are detrimental to the durability of the assembly, particularly in the context of dissimilar materials.

From a phenomenological point of view, it has been shown that these heterogeneities are related to the local tantalum content in the melting pool. The higher the tantalum content, the higher the starting temperature for solidification. More specifically, the areas that are the richest in tantalum (islets) start to solidify at $3269 \mathrm{~K}$ while those containing less tantalum (Ti-6Al-4V) solidify at approximately $1878 \mathrm{~K}$. The result is an arrangement of tantalum islets that are melted to varying degrees, located within a $\beta(\mathrm{Ti}, \mathrm{Ta})$ solid solution containing higher levels of tantalum near the islets. The creation of solidification defects and chemical heterogeneities is promoted by the short duration of the liquid phase (in the order of tens of milliseconds). These defects and heterogeneities are detrimental to the electrochemical behaviour of the welding
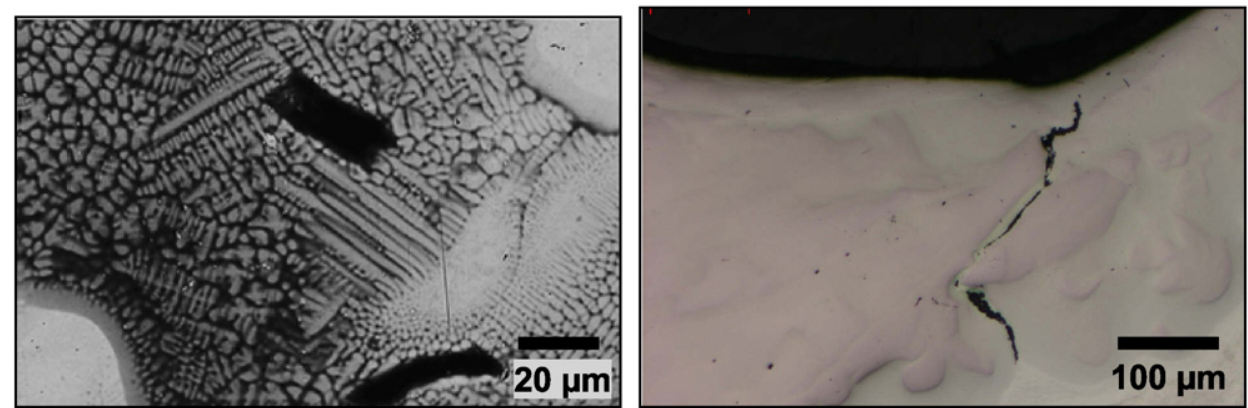

Fig. 13. Illustrations of existing defects in Sample $C$ when the beam is shifted towards tantalum. 

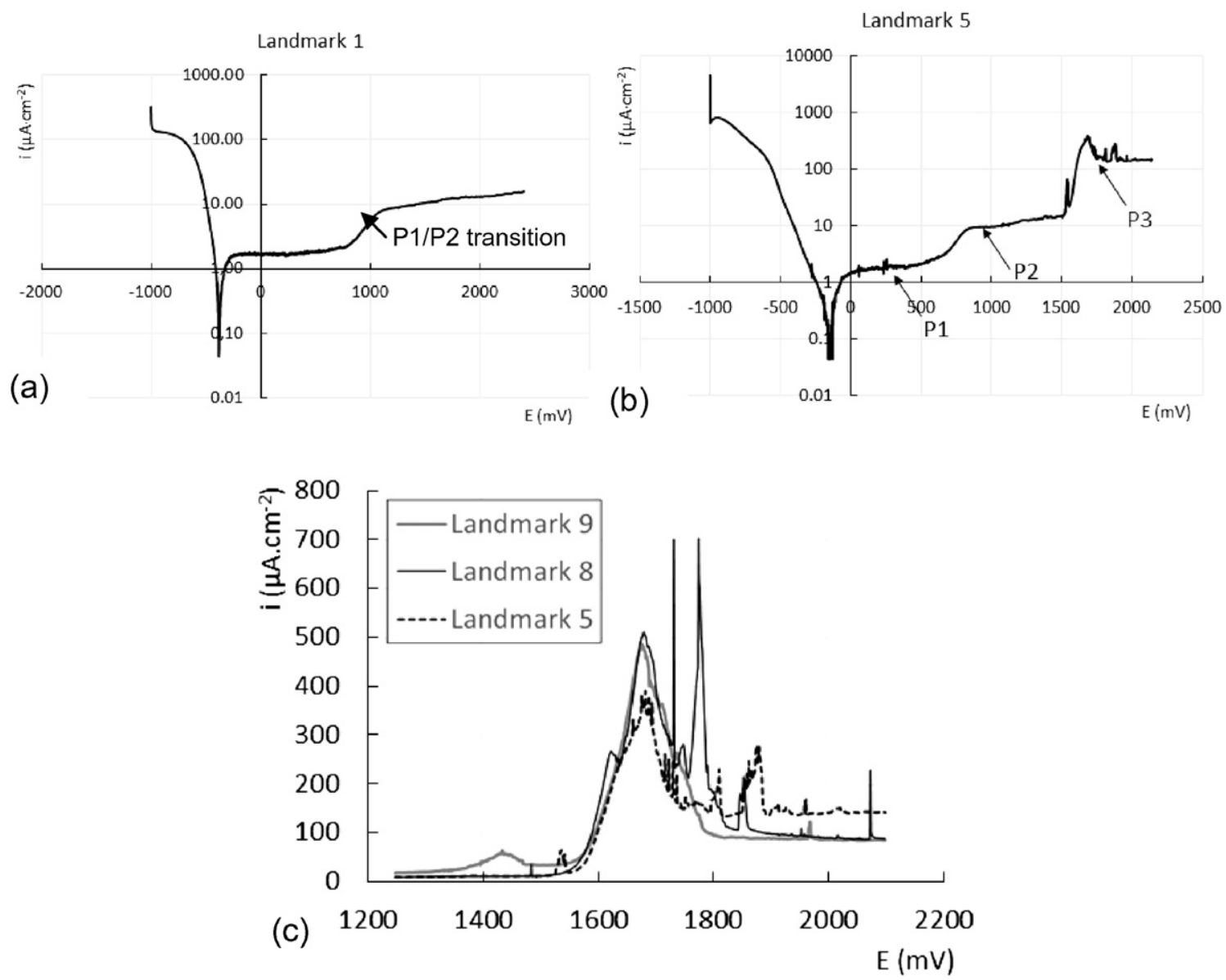

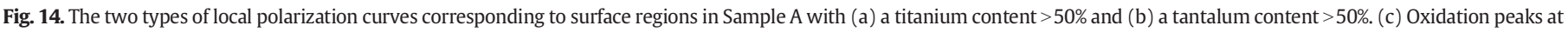
the P2/P3 transition and P3 plateau observed for different locations.

Table 5

Corrosion characteristics of various surface regions in Sample A.

\begin{tabular}{llclll}
\hline Landmark & $\begin{array}{l}\mathrm{Ti} \\
(\mathrm{wt} . \%)\end{array}$ & $\begin{array}{l}\mathrm{P} 1 / \mathrm{P} 2 \text { transition } \\
(\mathrm{mV})\end{array}$ & $\begin{array}{l}\mathrm{P} 3 \\
\text { existence }\end{array}$ & $\begin{array}{l}\mathrm{Al} / \mathrm{V} \\
\mathrm{i}\left(\mu \mathrm{A} \cdot \mathrm{cm}^{-2}\right) \\
\text { at }-750 \mathrm{mV}\end{array}$ \\
\hline 9 & 0 & 833 & Yes & - & - \\
8 & 11 & 930 & Yes & 1.7 & 143 \\
5 & 18 & 842 & Yes & 1.0 & 365 \\
2 & 37 & 963 & No & 1.0 & 569 \\
1 & 49 & 1095 & No & 1.5 & 33 \\
7 & 53 & 1070 & No & 2.0 & 83 \\
6 & 64 & 1136 & No & 1.3 & 323 \\
4 & 90 & 1429 & No & 1.5 & 23 \\
\hline
\end{tabular}

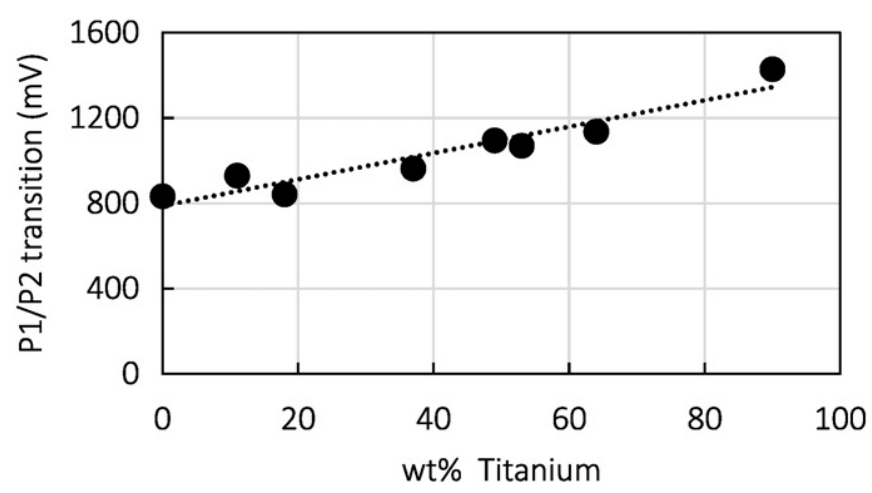

Fig. 15. Plot of transition potential between the two plateaus $\mathrm{P} 1$ and $\mathrm{P} 2$ against titanium content. seam, which is why it is important to try to attain greater homogeneity in the melting bath. However, a perfect blend is not possible because of the short duration of the liquid phase. Thus, a low tantalum content should be aimed for instead, and one way of achieving this is to preferentially melt the titanium alloy near the Ta-Ti interface. This ensures that only a small portion of the dissolved tantalum, which is in contact with the titanium liquid, is incorporated in the melting bath. From a practical point of view, the welding configuration can be reversed by shifting the beam

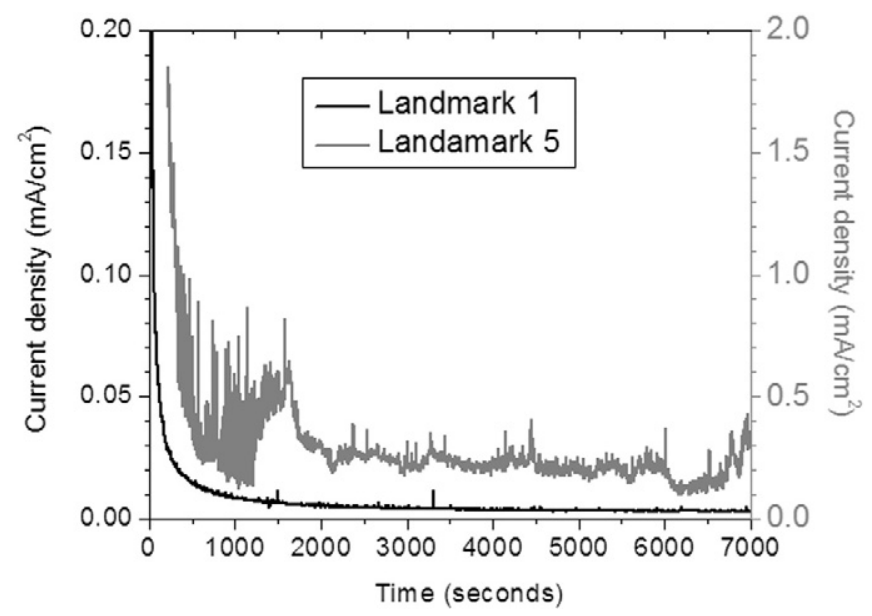

Fig. 16. Plot of current density against time during potentiostatic tests (at $2 \mathrm{~V} \mathrm{vs} . \mathrm{Ag} / \mathrm{AgCl}$ ) conducted at Landmarks 1 (black curve) and 5 (grey curve). 


\section{Landmark 2}

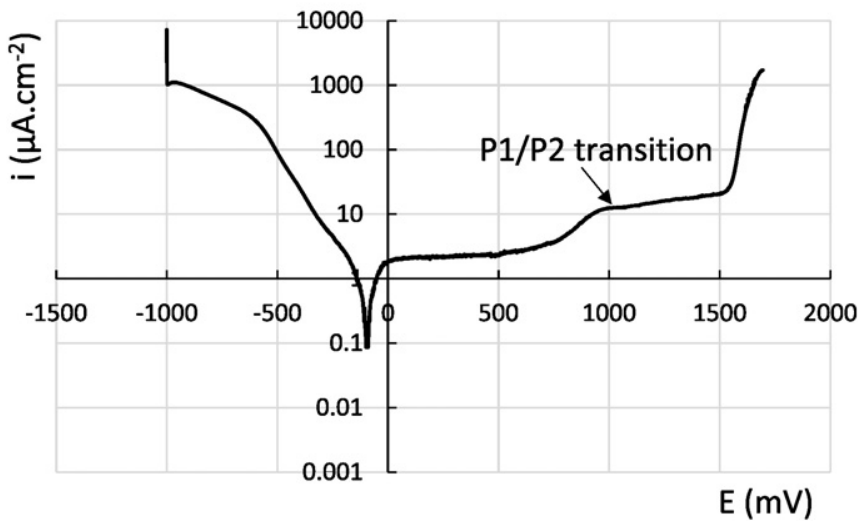

Fig. 17. Local polarization curve for Landmark 2 (Sample A).

towards the titanium plate in order to melt the titanium and encourage the dissolution of the tantalum by the liquid titanium. This was achieved in the present investigation by focusing a smaller laser beam (100 $\mu \mathrm{m}$ in diameter) on the titanium (100- $\mu \mathrm{m}$ shift away from the interface), and by reducing the laser power $(800 \mathrm{~W})$ and increasing the scanning speed $\left(7.2 \mathrm{~m} \cdot \mathrm{min}^{-1}\right)$.

The results of this beam shift are shown in Fig. 20. According to a macroscopic observation, fusion mainly affected the titanium alloy; also, heterogeneities are relatively sparse and, being widely dispersed and unmarked, did not lead to solidification defects. Based on a microscopic analysis, the tantalum-titanium mixing zone extends over a distance of approximately $20 \mu \mathrm{m}$. Furthermore, the microstructure of the melted zone is similar to that of Landmark 6 in Sample A, corresponding to a $\beta(\mathrm{Ta}, \mathrm{Ti})$ solid solution with a small amount of Ta. We have already shown that under the present test conditions, the corrosion behaviour mainly depends on the chemical composition (cf. Fig. 15 and Table 5). As the molten zone of Fig. 20 is between Landmarks 6 and 4 (see Table 5), we can assume that the corrosion behaviour of Landmarks 4-6 in Sample A is representative of that of the molten zone of the sample obtained with the optimized process, that is, the P1/P2 transition is close to $1.4 \mathrm{~V}$ and the $\mathrm{P} 3$ plateau does not exist.

\section{Conclusion}

This research has dealt with the impact of a difference in thermophysical properties on the laser welding of two dissimilar materials. We chose to study a titanium alloy (Ti-6Al-4V) and tantalum because of their good metallurgical compatibility and the possibility of focusing on the effects of thermophysical properties. A classical solution for successfully producing such an assembly is to shift the laser in the direction of the most refractory material (tantalum) to balance out the quantities of the two materials in the molten zone. This results in a molten zone comprising a $\beta(\mathrm{Ti}, \mathrm{Ta})$ solid solution containing tantalum islets that are melted to varying degrees. The mixture may be imperfect and the tantalum content of the solid solution may vary considerably between an overall value of $40 \%$ and local values of up to $80 \%$. These high local concentrations of tantalum act as solidification nuclei and result in an equiaxed structure, which is original for a weld
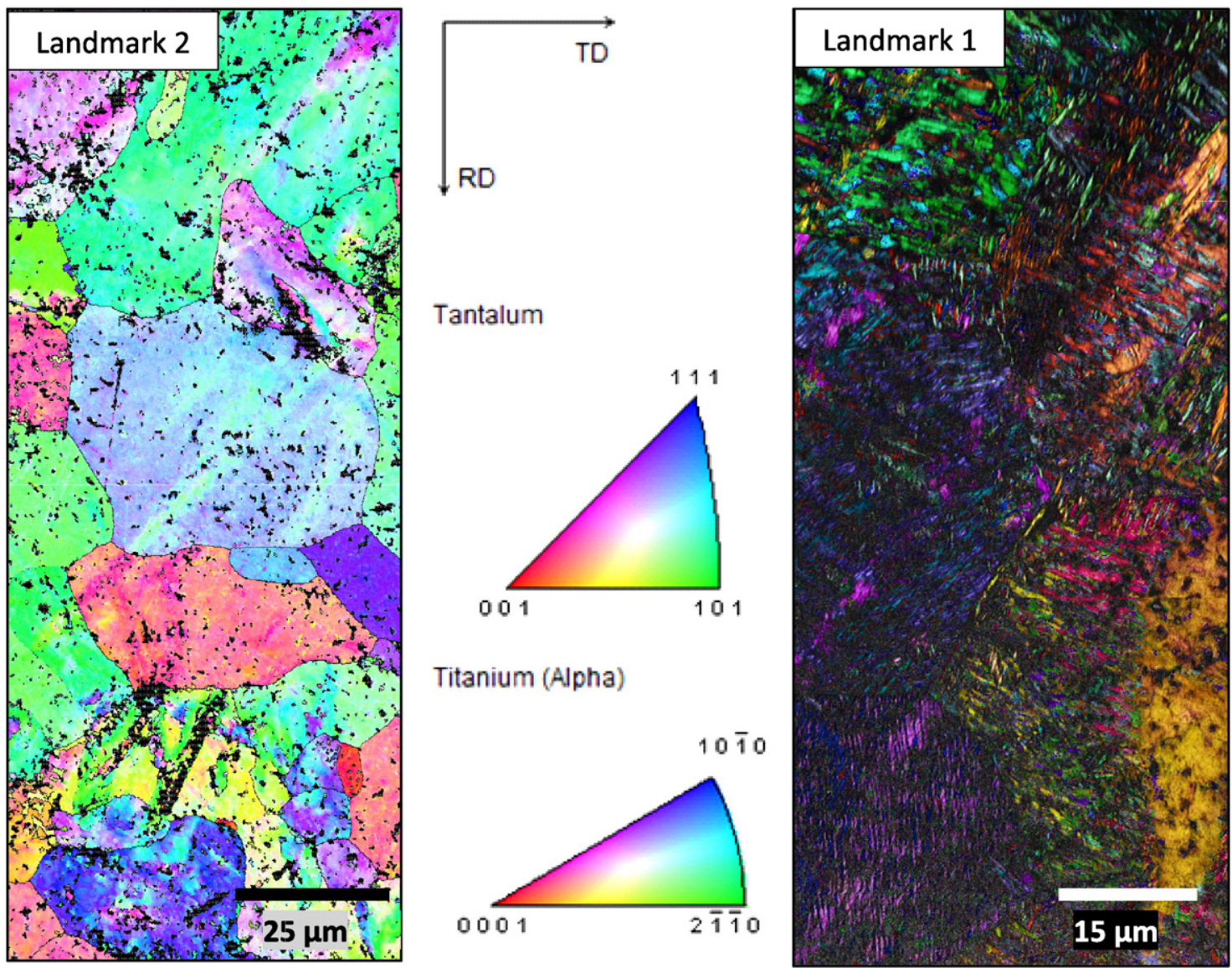

Fig. 18. EBSD observations (IPF map) conducted at Landmarks 1 and 2. 


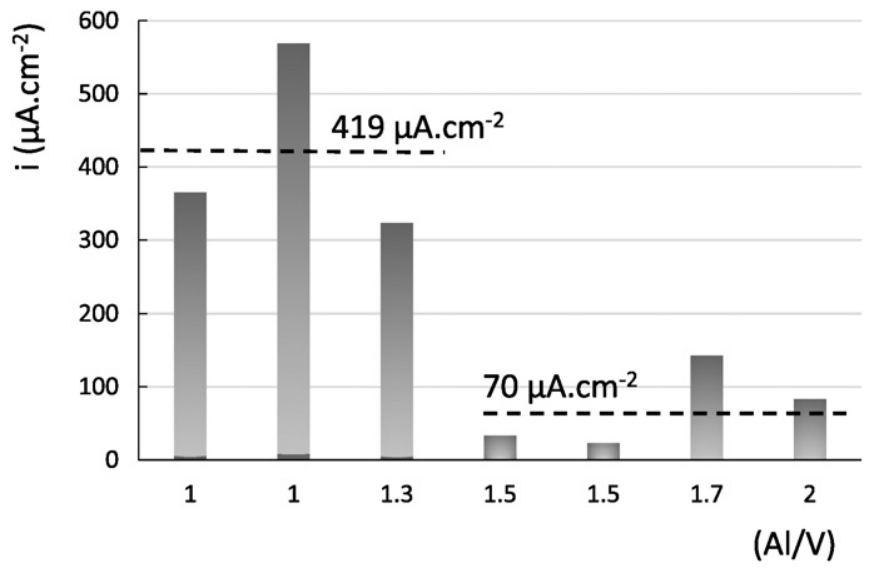

Fig. 19. Plot of current density, measured for an applied potential of $-750 \mathrm{mV}$ vs. $\mathrm{Ag} / \mathrm{AgCl}$, against the aluminium/vanadium ratio.

bead obtained by laser. Another consequence is the development of solidification defects such as microshrinkage.

An analysis of the electrochemical behaviour of different zones has shown that a high tantalum content (greater than $~ 50 \%$ ) leads to the formation of a passive film of lower quality compared to a situation with a high titanium content. In addition, the higher the titanium content, the more the passive film is able to retain its insulating properties at high potentials. In the cathodic domain, an $\mathrm{Al}: \mathrm{V}$ ratio higher than 1.4 promotes a lower cathodic current density. This leads us to propose an alternative method for the welding process that consists in shifting the energy source towards the least refractory material (Ti-6Al-4V) to promote the melting of Ti-6Al-4V and the dissolution of tantalum, which are enhanced by convection. By doing so, the molten zone has reduced and less extensive $(<30 \mu \mathrm{m})$ chemical heterogeneity. The result is an absence of solidification defects and a more protective passive film, even at high potentials.

\section{Acknowledgements}

This work was supported by the LabCom programme of the Agence Nationale de la Recherche of France. (ANR-13-LAB3-0005-01) The authors would like to thank the ARCEN nanocharacterization platform for providing us access to their facilities and for their scientific and technical assistance.

\section{Appendix A}

The purpose of present two-dimensional model is to show the influence of mismatch of thermo-physical properties on thermal field produced by laser heating of dissimilar junction (Fig. 21).

\section{A.1. Governing equations}

The interaction between the laser beam and the metallic vapour remains a complex problem. However, a simplified energy deposition is enough realistic to be used. The energy distribution of laser beam can be assumed to Gaussian-shaped and is consequently represented by:

$$
\begin{aligned}
& q_{1}=\frac{a_{1} \cdot P_{L}}{\pi \cdot R_{0}^{2}} \exp \left(-\frac{x^{2}}{R_{0}^{2}}\right) \cdot[x \leq 0] \\
& q_{2}=\frac{a_{2} \cdot P_{L}}{\pi \cdot R_{0}^{2}} \exp \left(-\frac{x^{2}}{R_{0}^{2}}\right) \cdot[x>0]
\end{aligned}
$$

where $P_{L}$ - laser power, $a_{1}$ and $a_{2}$ - absorption coefficients of Ti-6Al-4V and Ta respectively, $R_{0}$ - laser beam radius.

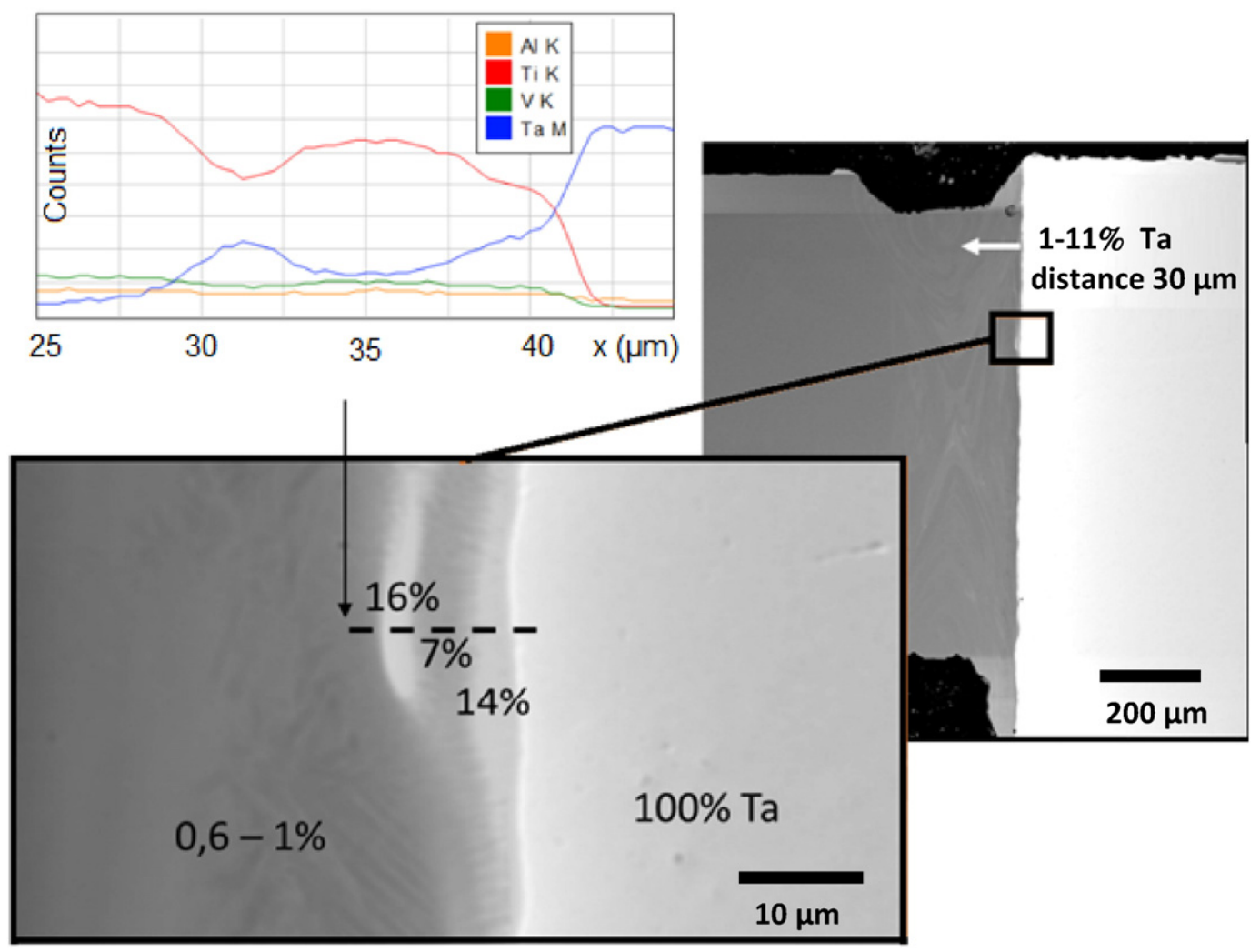

Fig. 20. SEM observation of the weld with a beam shift towards the titanium plate (tantalum contents in wt.\%). 


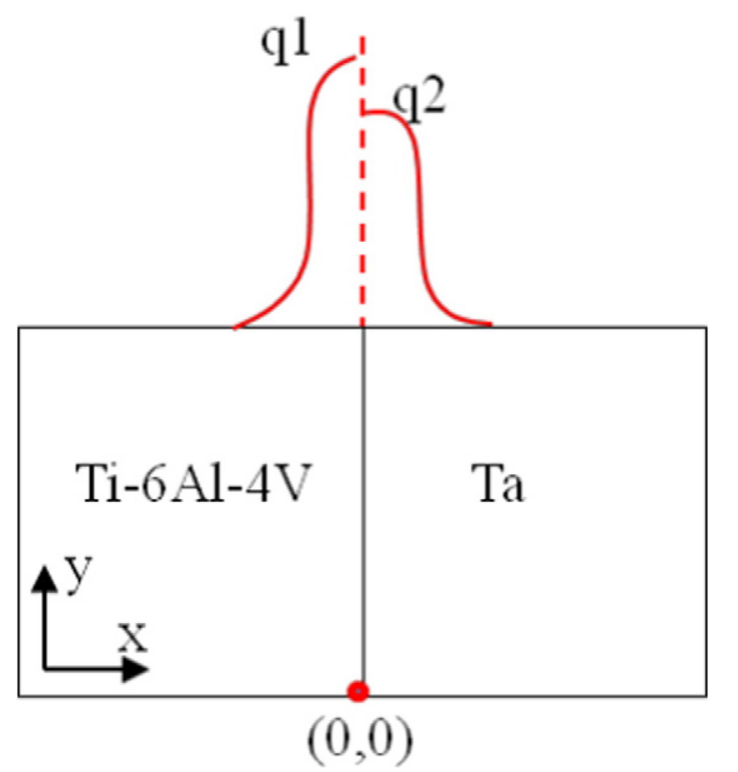

Fig. 21. Model geometry and position of Gaussian heat sources.

In order to evaluate the thermal field in the material as a function of time, energy equation is solved in its classical convection/diffusion form:

$\rho \cdot C_{p}^{e q}(T)\left[\frac{\partial T}{\partial t}+\vec{\nabla} T\right]=\vec{\nabla} \cdot(\lambda \vec{\nabla} T)$

where $\rho$ - density, $C_{p}^{e q}$ - equivalent heat capacity, $T$ - temperature and $\lambda-$ thermal conductivity.

\section{A.2. Phase change and thermophysical properties}

The change of thermophysical properties (Table 2) during fusion process is taken into account by using a Comsol function denoted flc2hs that corresponds to a continuous two times derivable Heaviside function. This function allows smooth variation of thermophysical

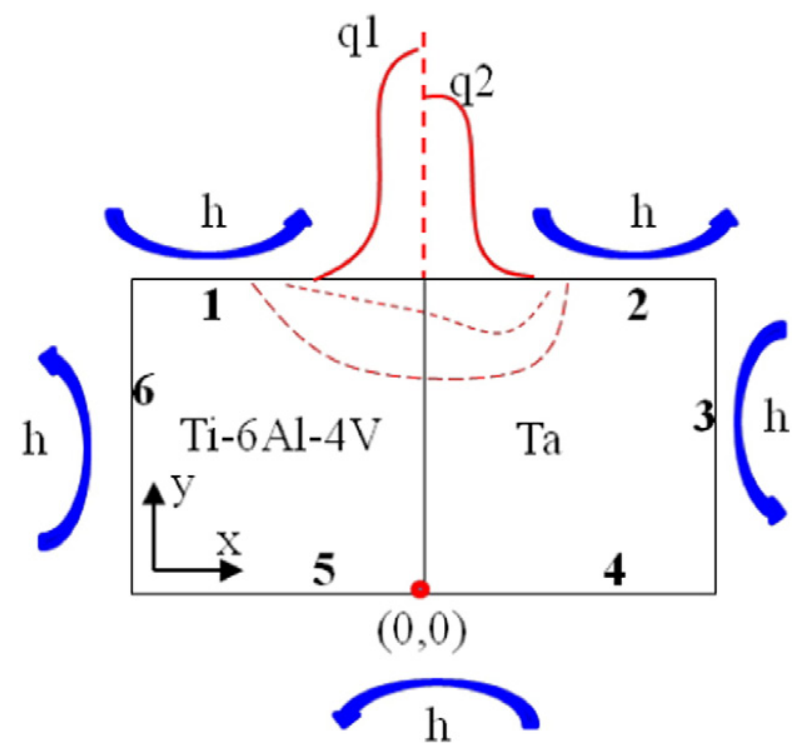

Fig. 22. Boundary conditions. properties during passage from solid state value $A_{s}$ to liquid state value $A_{l}$ within temperature range $2 \Delta \mathrm{T}$ centred on fusion temperature $T_{f}$ :

$A=A_{s}+\left(A_{1}-A_{s}\right) \cdot f l c 2 h s\left(T-T_{f}, \Delta T\right)$.

Additionally, specific heat capacity function takes into account latent heat of fusion $L_{f}$ :

$\mathrm{C}_{\mathrm{p}}^{\mathrm{eq}}=\mathrm{C}_{\mathrm{p}}+L_{f} \cdot \frac{\exp \left(-\frac{\left(T-T_{f}\right)^{2}}{(\Delta T)^{2}}\right)}{\sqrt{\pi \Delta T^{2}}}$.

where $T_{f}$ - melting point, $L_{f}$ - latent heat of fusion and $\Delta \mathrm{T}-$ smoothing parameter set to $50 \mathrm{~K}$.

\section{A.3. Boundary conditions}

During welding, the work piece surfaces are exposed to heat losses by natural convection and heat radiation (Fig. 22). Heat source representing energy distribution of laser beam is introduced as a boundary condition on top surface of the plates (boundary 1). For other boundaries, convective heat flux and heat radiation conditions are considered by using global heat transfer coefficient, $h=15 \mathrm{~W} \cdot \mathrm{m}^{2} \cdot \mathrm{K}^{-1}$.

Boundary (1) $\quad \lambda \vec{\nabla} T \cdot \vec{n}=q_{1}-h\left(T-T_{0}\right)$

Boundary (2) $\quad \lambda \vec{\nabla} T \cdot \vec{n}=q_{2}-h\left(T-T_{0}\right)$

Boundaries $(3,4,5,6) \quad \lambda \vec{\nabla} T \cdot \vec{n}=-h\left(T-T_{0}\right)$

where $T_{0}=300 \mathrm{~K}$.

\section{References}

[1] J. Fan, C. Thomy, F. Vollertsen, Effect of thermal cycle on the formation of intermetallic compounds in laser welding of aluminum-steel overlap joints, Phys. Procedia 12 (A) (2011) 134-141.

[2] K. Devendranath Ramkumar, S.D. Patel, S. Sri Praveen, D.J. Choudhury, P. Prabaharan, N. Arivazhagan, M. Anthony Xavior, Influence of filler metals and welding techniques on the structure-property relationships of Inconel 718 and AISI 316 L dissimilar weldments, Mater. Des. 62 (2014) 175-188.

[3] R.S. Coelho, A. Kostka, J.F. dos Santos, A. Kaysser-Pyzalla, Friction-stir dissimilar welding of aluminium alloy to high strength steels: mechanical properties and their relation to microstructure, Mater. Sci. Eng. A 556 (2012) 175-183.

[4] S.H. Baghjari, S.A.A. Akbari Mousavi, Experimental investigation on dissimilar pulsed Nd:YAG laser welding of AISI 420 stainless steel to kovar alloy, Mater. Des. 57 (2014) 128-134.

[5] H.M. Li, D.Q. Sun, X.L. Cai, P. Dong, W.Q. Wang, Laser welding of TiNi shape memory alloy and stainless steel using Ni interlayer, Mater. Des. 39 (2012) 285-293.

[6] D. Ren, L. Liu, Interface microstructure and mechanical properties of arc spot welding Mg-steel dissimilar joint with Cu interlayer, Mater. Des. 59 (2014) 369-376.

[7] Y. Hu, X. He, G. Yu, Z. Ge, C. Zheng, W. Ning, Heat and mass transfer in laser dissimilar welding of stainless steel and nickel, Appl. Surf. Sci. 258 (2012) 5914-5922.

[8] I. Tomashchuk, P. Sallamand, J.M. Jouvard, D. Grevey, The simulation of morphology of dissimilar copper-steel electron beam welds using level set method, Comput. Mater. Sci. 48 (2010) 827-836.

[9] C.W. Tan, Z.G. Jiang, L.Q. Li, Y.B. Chen, X.Y. Chen, Microstructural evolution and mechanical properties of dissimilar Al-Cu joints produced by friction stir welding, Mater. Des. 51 (2013) 466-473.

[10] X. Wang, X. Li, C. Wang, Effect of two-step heating process on joint microstructure and properties during transient liquid phase bonding of dissimilar materials, Mater. Sci. Eng. A 560 (2013) 711-716.

[11] J. Hossick-Schott, M. Reiterer, J. Heffelfinger, M. Hintz, M. Ringle, I. Levina, K. Gaffney, Latent cracking of tantalum-titanium welds due to hydrogen embrittlement, J. Miner. Met. Mater. Soc. 65 (2003) 625-629.

[12] K. Nishio, H. Masumoto, H. Matsuda, H. Ikeda, Diffusion bonding of tantalum to titanium, Quart. J. Jpn. Weld. Soc. 21 (2003) 302-309.

[13] S. Pineau, M. Veyrac, M. Hourcade, B. Hocheid, The Investigation and Production of Titanium-Tantalum Junctions Diffusion Bonded at HighTemperature $\left(855^{\circ} \mathrm{C}\right.$ to $920^{\circ} \mathrm{C}$ ): the Influence of Temperature, Time Pressure and Roughness on the 
Mechanical Properties, and the Optimisation of the Bonded Conditions, J. Less-Common Met. 109 (1985) 169-196.

[14] A. Malicrot, Etude de la formation et des propriétés physiques des zones fondues dans le cas de l'assemblage du tantale avec l'alliage de titane TA6VPhD thesis Université de Bourgogne, France, 2008.

[15] Y.L. Zhou, M. Niinomi, T. Akahori, M. Nakai, H. Fukui, Comparison of various propertie between Titanium-Tantalum alloy and pure titanium for biomedical applications, Mater. Trans. 48 (2007) 380-384.

[16] Y.L. Zhou, M. Niinomi, T. Akahori, H. Fukui, H. Toda, Corrosion resistance and biocompatibility of Ti-Ta alloys for biomedical applications, Mater. Sci. Eng. 398 (A) (2005) 28-36.

[17] K. Alves de Souza, A. Robin, Influence of concentration and temperature on the corrosion behavior of titanium, titanium-20 and 40\% tantalum alloys and tantalum in sulfuric acid solutions, Mater. Chem. Phys. 103 (2007) 351-360.

18] H. Okamoto, Ta-V (tantalum-vanadium), J. Phase Equilib. Diffus. 26 (2005) 134-141.

[19] M. Vänskä, F. Abt, R. Weber, A. Salminen, T. Graf, Effects of welding parameters onto keyhole geometry for partial penetration laser welding, Phys. Procedia 41 (2013) 199-208.
[20] R. Fabbro, Developments in Nd-Yag laser welding, in: S. Katayama (Ed.), Handbook of Laser Welding Technologies, Woodhead Publishing Limited, Oxford 2013, pp. 47-72.

[21] R. Fabbro, S. Slimani, F. Coste, F. Briand, Study of keyhole behaviour for full penetration Nd-Yag CW laser welding, J. Phys. D. Appl. Phys. 38 (2005) 1881-1887.

[22] I. Bendaoud, S. Mattei, E. Cicala, I. Tomashchuk, P. Sallamand, A. Mathieu, H. Andrzejewski, F. Bouchaud, The numerical simulation of heat transfer during a hybrid laser-MIG welding using equivalent heat source approach, Opt. Laser Technol. 56 (2014) 334-342.

[23] H. Krawiec, S. Staneka, V. Vignal, J. Lelito, J.S. Suchya, The use of microcapillary techniques to study the corrosion resistance of AZ91 magnesium alloy at the microscale, Corros. Sci. 53 (2011) 3108-3113.

[24] H. Krawiec, V. Vignal, E. Schwarzenboeck, J. Banas, Role of plastic deformation and microstructure in the micro-electrochemical behaviour of Ti-6Al-4V in sodium chloride solution, Electrochim. Acta 104 (2013) 400-406. 